\title{
Electrochemical ECG grinding of ceramic and tungsten sinter
}

\author{
Krzysztof Przystupa ${ }^{1}$ \\ ${ }^{1}$ Lublin University of Technology, Department of Automation, Nadbystrzycka 36, 20-618 Lublin, Poland
}

\begin{abstract}
The article describes a process of electrochemical grinding (ECG - Electrochemical Grinding) with a rectangular diamond grinding wheel made of ceramic - tungsten frit. Treatment of this type of material is very difficult, not only because of adverse physical properties of material itself but also due to very high requirements resulting from conditions of exploitation of a product. In discussed case, the process was carried out for a workpiece consisting of 8 tiles with a total area of about $110 \mathrm{~cm} 2$, fastened by screwing to a machine tool table. The article analyses a course of a chemical process, presenting chemical reactions and the course of an electrical process, closely related to a flow of electric current. Particular attention was paid to the flow of electric current as a function of changes in an active surface, understood as a geometric surface through which the electric current can flow. The results of calculation for this surface and an example of a shape of the recorded current waveform are shown. The presented results were used in construction of a control system based on maintaining a constant density of the working current.
\end{abstract}

\section{Introduction}

Parts made of ceramic-tungsten sinter are used in electronic and power engineering; particularly, contacts of electrical apparatus, temperature compensators and power elements in rectifiers and thyristor devices, as well as durable, heat-resistant elements, fuel-transporting elements of rocket engines and space craft components [1-2].

This is because this material has unique properties, e.g. high hardness, high mechanical and chemical resistance as well as uniform quality characteristics of the surface layer [3-6].
The problem of processing such materials concerns mainly small surfaces (generally up to $25 \mathrm{~cm}^{2}$ ), and seldom large ones (over $200 \mathrm{~cm}^{2}$ ), with thickness of tiles from 1 to $6 \mathrm{~mm}$. Such plates are characterised by very limited flexibility and require a special approach to their attachment. Most often this is done by vacuum clamping. In the analysed case, the plate consisted of 8 pcs. elementary tiles with dimensions of $31 \times 44 \times 10 \mathrm{~mm}$ with a total surface area of $109.12 \mathrm{~cm} 2$. Elemental plates were combined into a test sample by soldering on a steel plate, which was attached to a table's working surface by screwing (Fig. 1).

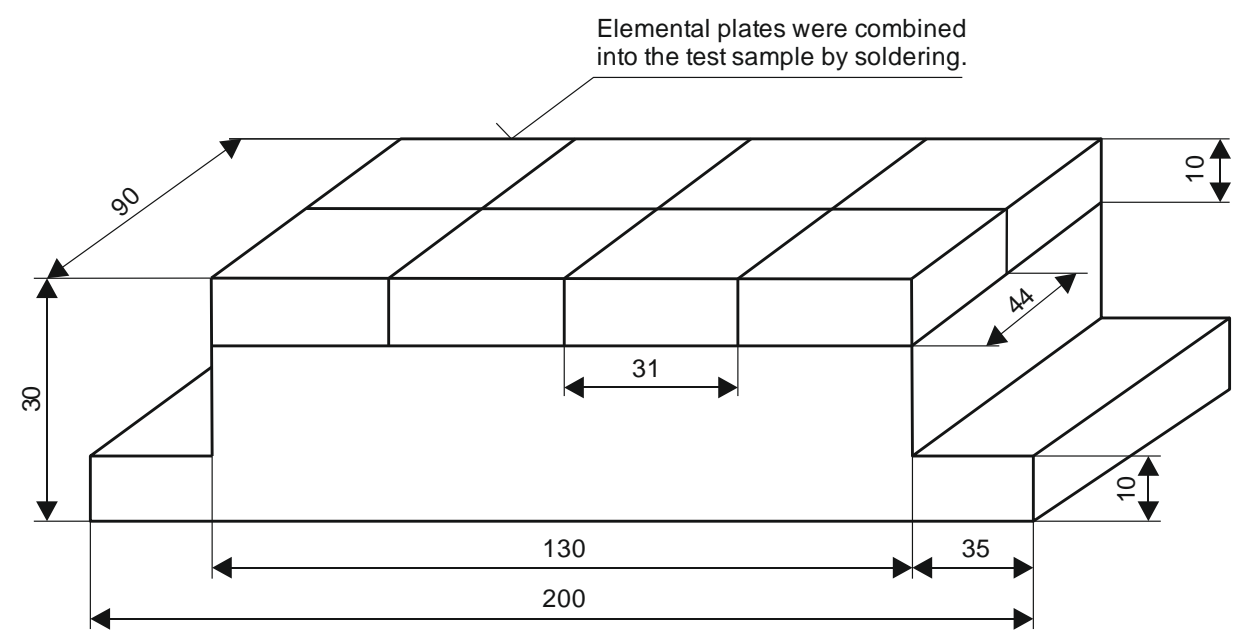

Fig. 1. Test sample.

*Corresponding author: k.przystupa@pollub.pl 
The machining process, its quality and the quality of an obtained surface after machining largely depend on matching right proportions of various energy forms delivered to a machining zone [7-12]. During the process, two forms of energy dominate: electrochemical. Energy associated with chemical reactions and the flow of electric current and mechanical energy associated with energy of classical cutting [13-14]. The article concerns elimination of problems related to electrochemical energy, considering the division of this energy into chemical and electrical as unjustified.

\section{Experiment}

In the grinding process, a $12 \mathrm{~A} 2$ diamond face $200 \times 20 \times$ 5 AC6 100/80 100\% was used (glued onto a silver basis).

The following machining parameters were adopted: longitudinal feed speed $100 \mathrm{~mm} / \mathrm{min}$, tool speed 1500 rpm; vertical feed with a $0.01 \mathrm{~mm}$ pitch; work movement with a length ensuring complete grinding of the grinding wheel. The operating voltage of electrodes was optimised in a range from 2.5 to $5 \mathrm{~V}$, depending on a relative value of a tool and workpiece position. Constant flow of electrolyte supplied by two external nozzles flow forced by a pump and through 4 nozzles built into the grinding wheel housing - gravity flow, assisted by centrifugal force, a total of max. $181 / \mathrm{min}$, without cutting the flow off after cutting through the machining zone. The electrolyte was an aqueous solution of $\mathrm{Na}_{2} \mathrm{HPO}_{4}$ with addition of $\mathrm{Na}_{2} \mathrm{CO}_{3}$. During the process, the $\mathrm{pH}$ of the electrolyte was changed from 9.5 to 10.25 . Changes have not been corrected.

\subsection{Chemical energy}

Chemical reactions during processing can be generalised and divided into four groups:

- Electrolytic dissociation reactions:

$\mathrm{H}_{2} \mathrm{O} \rightarrow \mathrm{H}^{+}+\mathrm{OH}^{-}$.

- Cathode reactions (Fig. 2.) :

$M e^{n+}+n e^{-} \rightarrow M e ;$

$2 H+2 e \rightarrow 2 H^{+} \uparrow$.

- Anode reactions (Fig. 2.):

$M e \rightarrow M e^{n+}+n e^{-}$;

$4 \mathrm{OH}^{-} \rightarrow \mathrm{O}_{2}+2 \mathrm{H}_{2} \mathrm{O}+4 e^{-}$;

$2 \mathrm{H}_{2} \mathrm{O} \rightarrow \mathrm{O}_{2}+4 \mathrm{H}^{+}+4 e^{-}$.

- Electrode reactions:

$M e^{n+}+n A^{-} \rightarrow M e A_{n}$

$M e^{n+}+n \mathrm{OH}^{-} \rightarrow \mathrm{Me}(\mathrm{OH})_{n} \downarrow$

where :

$M e$ - removed metal,

$A$ - removed metal's ion.

Detailed reactions taking place in this process have the following form:

$$
\begin{aligned}
& \mathrm{H}_{2} \mathrm{O}+2 \bar{e} \rightarrow \mathrm{H}^{+} \uparrow+\mathrm{OH}^{-} \\
& 2 \mathrm{H}_{\uparrow}+2 \bar{e} \rightarrow 2 \mathrm{H}^{+} \uparrow ; \\
& W+6 \mathrm{OH}^{-} \rightarrow \mathrm{WO}_{3}^{3-}+3 \mathrm{H}_{2} \mathrm{O} ; \\
& W+8 \mathrm{OH}^{-} \rightarrow \mathrm{WO}_{4}^{2-}+4 \mathrm{H}_{2} \mathrm{O}+6 \bar{e} ;
\end{aligned}
$$

$$
\begin{aligned}
& \mathrm{WO}_{4}^{2-}+2 \mathrm{H}^{+} \uparrow \rightarrow \mathrm{H}_{2} \mathrm{WO}_{4} ; \\
& \mathrm{WO}_{4}^{2-}+2 \mathrm{H}_{2} \mathrm{O} \rightarrow \mathrm{H}_{2} \mathrm{WO}_{4 \downarrow}+2 \mathrm{OH}^{-} ; \\
& \mathrm{Na}_{2} \mathrm{HPO}_{4}+\mathrm{H}_{2} \mathrm{O} \leftrightarrow \mathrm{NaOH}+\mathrm{NaH}_{2} \mathrm{PO}_{4} ; \\
& \mathrm{Na}_{2} \mathrm{HPO}_{4} \leftrightarrow 2 \mathrm{Na}^{+}+\mathrm{HPO}_{4}^{2-} ; \\
& \mathrm{HPO}_{4}^{-2}+\mathrm{OH}^{-} \leftrightarrow \mathrm{PO}_{4}^{3-}+\mathrm{H}_{2} \mathrm{O} ; \\
& 2 \mathrm{Na}_{2} \mathrm{CO}_{3}+2 \mathrm{H}_{2} \mathrm{O} \leftrightarrow 2 \mathrm{NaOH}+2 \mathrm{NaHCO}_{3} ; \\
& \mathrm{WO}_{3}^{3-}+2 \mathrm{NaOH} \rightarrow \mathrm{Na}_{2} \mathrm{WO}_{4}+\mathrm{H}_{2} \mathrm{O} . \\
& \mathrm{PO}_{4}^{3-}+2 \mathrm{H}_{2} \mathrm{O} \leftrightarrow \mathrm{H}_{2} \mathrm{PO}_{4}^{2-}+2 \mathrm{OH}^{-} ; \\
& \mathrm{HPO}_{4}^{2-}+\mathrm{H}_{2} \mathrm{O} \leftrightarrow \mathrm{H}_{2} \mathrm{PO}_{4}^{-}+\mathrm{OH}^{-} ;
\end{aligned}
$$

As a result of the presented reactions, tungsten is removed from a treated surface while maintaining a constant electrolyte reaction [15].

\subsection{Electric energy}

The machining process, its quality and the quality of the surface after machining depend largely on the selection of electrical parameters. The decisive magnitude is intensity of the electric current flowing through the treatment zone. The value of the electric current is most easily influenced by changing the voltage between the electrodes (grinding wheel and workpiece) [16-17]. In the process, the current flows between the wheel and the plate being machined only at the place where the grinding wheel contacts the material (Fig. 2).

This surface is equal to a sum of a contact area of the face and the side surface of the grinding wheel with the workpiece (Fig. 2). It seems that a lateral surface can have significantly worse electrolyte flow conditions, but at the same time, that is in most cases mainly due to a low value of the grinding depth significantly smaller than the face.

It is easy to find a description of the problem with evaluation of the grinding wheel Active Surface in classical grinding in the literature. The main purpose of works described in the literature is to assess and predict the usable properties of compact tools in the grinding process. The course of proceedings in such studies usually includes [18-20]:

- mapping the perimeter profile of the active grinding wheel surface (with the help of a suitable grinding wheel profilometer),

- computer simulation of the grinding process,

- analysis of statistical parameters resulting from this simulation,

- formulating conclusions about the state of CPS.

Research aimed at the presented direction is very important from the point of view of, for example, the quality of the treated surface, however, it is not very useful from the point of view of the electrochemical grinding process control (DECMG). Therefore, it is important to find the relationship between the instant active surface area in the grinding process and the position of the workpiece relative to the grinding wheel. Determined dependence is necessary to estimate instantaneous density of the dissolution current, whose size plays a major role in the discussed process, because it determines intensity of the electrolysis process. 


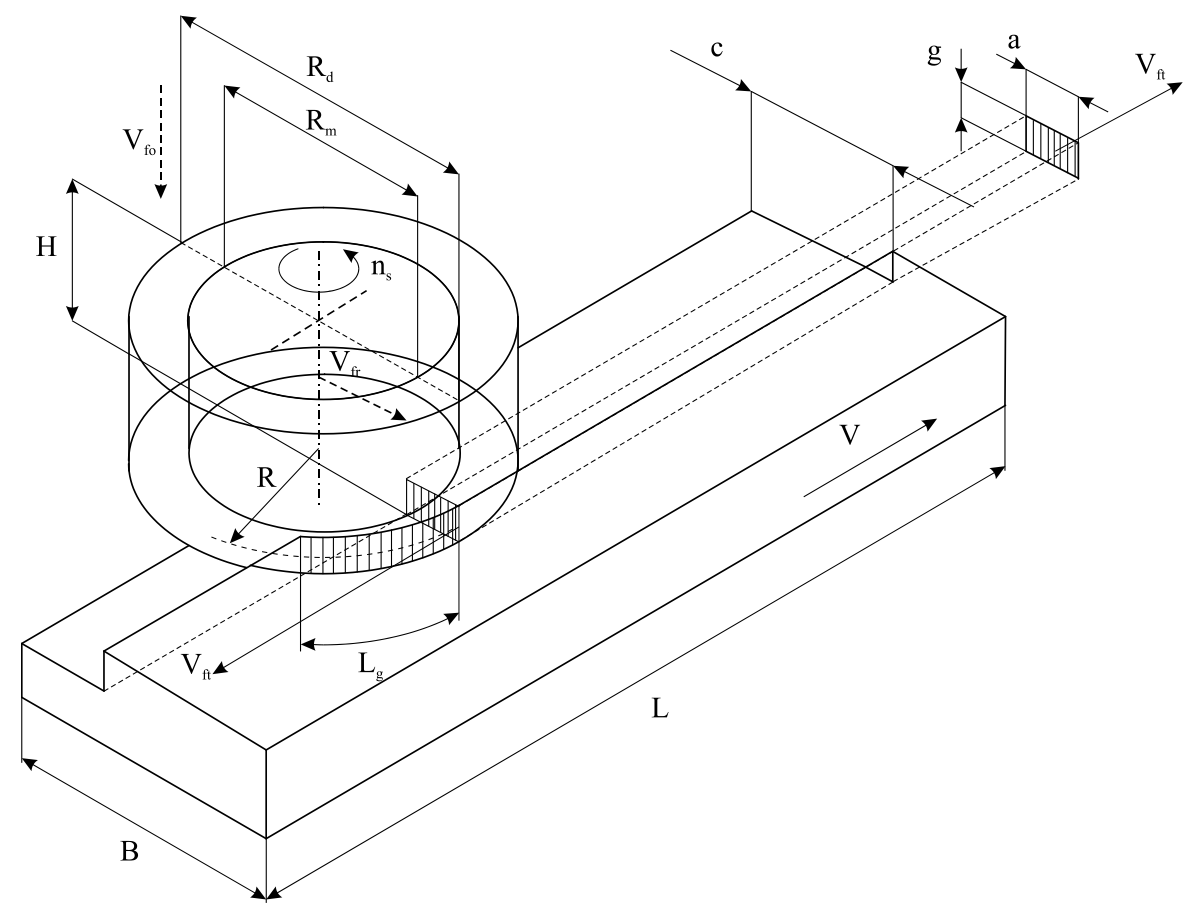

Fig. 2. Geometric quantities related to the electrochemical grinding process.

\section{Results}

The problem of calculating the contact surface of the grinding wheel with an object can be considered in three mathematical approximations:

1. The grinding wheel touches the object only with the face (mathematically simple case, completely ignores the lateral surface of the grinding wheel).

2. The grinding wheel contacts the object with the face and lateral surface defined by a rectangle with an area of $a \cdot g$ (Fig. 2).

3. The grinding wheel contacts the object with the face and lateral surface indicated in Fig. 2. with the dimension $L_{g}$.

The first approximation is the easiest to carry out mathematical calculation for but at the same time the least accurate. In this work, this case was considered.

To determine the course of changes in the contact surface of the grinding wheel face with the workpiece, one of the following methods should be used:

\subsection{Method 1.}

It consists in solving a geometric task with the following content: one should designate the common part of the grinding wheel and workpiece, if the grinding wheel and material are fixed to each other. For this purpose, geometric relationships should be used. Then, for given quantities, the common part of fields should be calculated many times.

\subsection{Method 2.}

It also requires multiple calculation of the common field but does not require such a complicated geometric analysis. For this purpose, we assume that the common part of the fields can be covered with a grid, such as on a piece of graph paper and check the grille on the grid whether it is inside the considered area. Grilles completely included in the assumed area should be counted. The disadvantage of this method is the large number of grids which should be checked, which significantly extends the time of making calculation. The accuracy of the calculated field depends on the size of the elementary field of the grille.

\subsection{Method 3}

It consists in covering the area of interest with a randomly selected rectangle. Then the rectangle should be divided in half and we check which part is inside the area. When you get half of the rectangle completely contained in the field in question, you should deal with the other half by dividing it in half and checking which half is completely in the field under investigation.

You proceed in this way until obtaining a rectangle with a minimum size, insignificant for the accuracy of the measurement. At the same time, the fields of completely contained rectangles must be added up. The division of the rectangle should be performed alternately: vertically and horizontally. The advantage of this method is a very simple algorithm, which can be relatively easily saved in any programming language. The disadvantage is the small accuracy depending on the time of the operation of calculating the sum of fields.

The presented description shows that only the first method gives the accuracy required in electrochemical grinding and this method was used in calculation. The main stages of calculating the algorithm will be presented below.

To determine the relationship between the position of the workpiece and the contact surface of the material and grinding wheel, the following simplifications have been adopted:

- the grinding wheel touches the entire surface with the material,

- the momentary position of the rectangle (workpiece) is known, 
- the internal diameter of the grinding wheel is temporarily omitted.

To further simplify the considerations, Cartesian coordinate system with the beginning coinciding with the centre of the grinding wheel was introduced (Fig. 3).

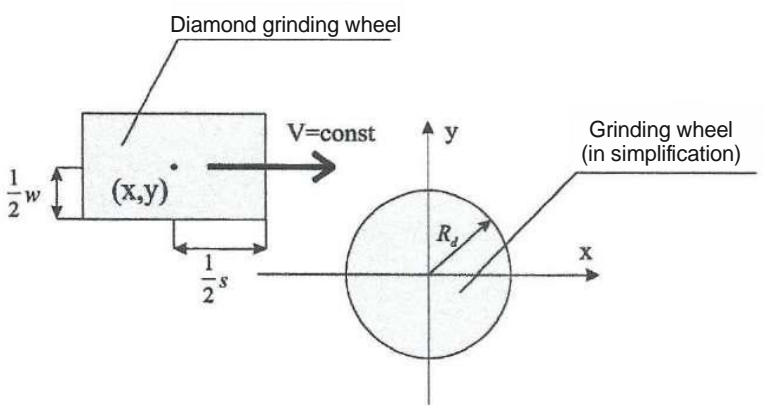

Fig. 3. Geometric values characterising the adopted coordinate system used to calculate the contact surface of the grinding wheel with the workpiece.
It was then assumed that the position of the workpiece relative to the grinding wheel is determined by the coordinates of the rectangular centre of the workpiece (Fig. 3). Dimensions are defined by half width (s) - longer side and half height (w) - shorter side. To simplify the considerations, the coordinate system was limited to the first quadrant, therefore, $1 / 4$ of the grinding wheel of the grinding wheel is analysed (Fig. 4).

Fig. 4. shows that the common part of the workpiece with the disc corresponds to the intersection of the right angle with the quadrant of the circle in the first quadrant of the coordinate system. This means that the field is 4 times larger than that calculated in Fig. 4.

A further solution to the task is a simple geometric analysis. As a result, the equation which graphic image is shown in Fig. 5. was obtained. For calculation, it was assumed that the grinding wheel has an external radius (R) $75 \mathrm{~mm}$, and internal (r) $55 \mathrm{~mm}$, workpiece dimensions according to Fig. 1. are respectively (w, s) 45 and $65 \mathrm{~mm}$. The dimensions defined as «Length of the rectangle» and «Width of the rectangle» (Fig. 5) in fact mean the dimensions of the machined surface, referred to the centre of a cut board (x, y) - Fig. 3 .
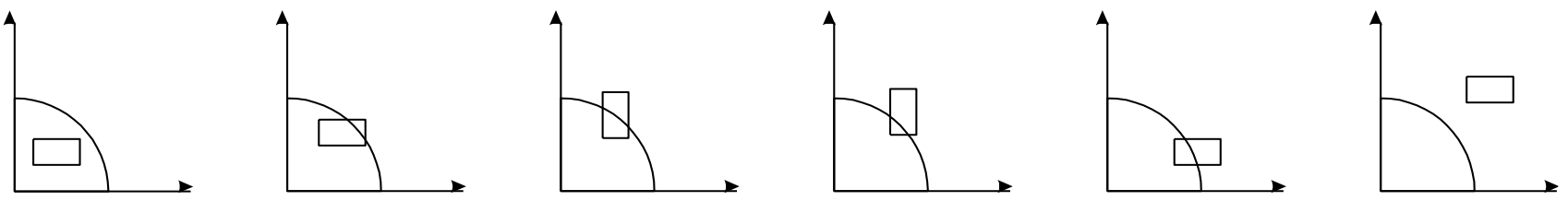

Fig. 4. Positions that the treated material can take in relation to the grinding wheel.

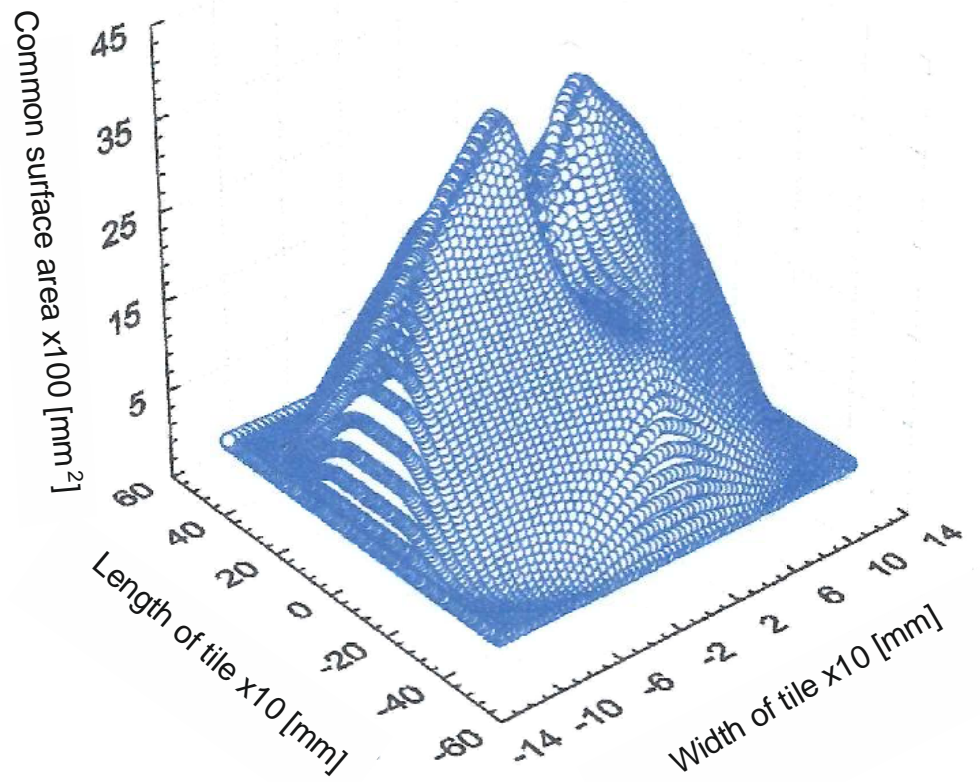

Fig. 5. Change of contact surface of grinding wheel and workpiece during grinding determined by Method 1 . 
a)

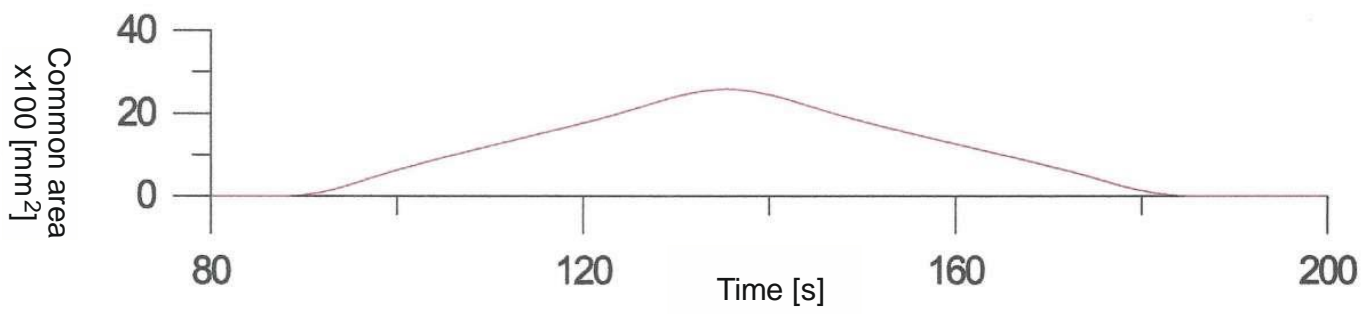

b)

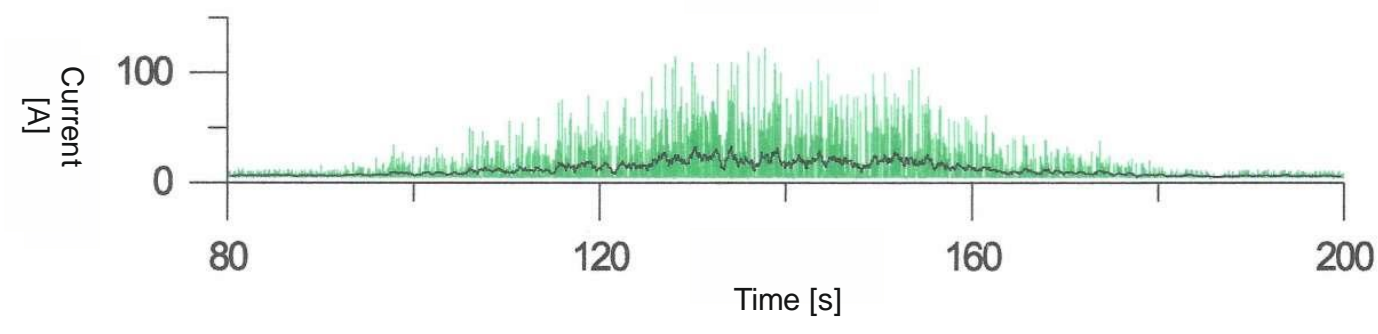

Fig. 6. The basic magnitudes characterising the electrochemical grinding process, (a) the approximate surface of the contact between the grinding wheel and the workpiece, (b) operating current.

\section{Conclusion}

The obtained results of the theoretical analysis, shown in Fig. 5, allowed to develop the equation determining the change of the contact surface of the object and the grinding wheel (Fig. 6a). By proportionally modifying the field (Fig. 6a) in the voltage between the grinding wheel and the workpiece, a registered course of the working current was obtained (Fig. 6b).

The experiment was carried out for the grinding depth of $25 \mu \mathrm{m}$, speed of $0.003 \mathrm{~m} / \mathrm{s}$, maximum dissolution tension of $5 \mathrm{~V}$, and cutting width of $40 \mathrm{~mm}$.

For the assumed geometric quantities (mainly cutting width), the area with a constant momentary contact surface of the grinding wheel with the workpiece could not be obtained (Fig. 6a). Fig. 6b. shows the current value of the dissolution current (green) and the average value MA (21) (black). There is a visible increase in the instantaneous dissolution current along with the increase in the contact area of the machined plate with the grinding wheel. Presented results will be used to build a control system optimising a share of electricity in the machining process.

\section{References}

1. T.J. Walz, Adv Mater Process. 163, 1 (2005)

2. C.T. Miclea, M. Cioangher, C.F. Miclea, S. Spanulescu, R. Faibis, Proceedings of the International Semiconductor Conference, CAS 2,6400781 (2012)

3. M.E. Drits, Publishing House Metallurgiya (Mir Publishers, Moscow 1985)
4. A.V. Bobylev, Moscow: Publishing House Metallurgiya (Mir Publishers, Moscow 1980)

5. A. T. Vasko, Kiev: Publishing House Engineering, (Mir Publishers, Moscow 1969)

6. V.D. Chupov, Yu N. Vil'k, V. V. Dmitriev, G.P. Zajtsev, Ogneupory $i$ Tekhnicheskaya Keramika, (4), (2000)

7. T. Kurita, C. Endo, Y. Matsui, Int J Mach Tool Manu 48 (15) (2008)

8. T. Kurita, M. Hattori, Int J Mach Tool Manu 46 (14) (2006)

9. V.A. Mogilnikov,M. Y. Chmir, Y. S. Timofeev, CIRP 2013, 6 (2013)

10. A.F. Tehrani, J. Atkinson, PI Mech Eng B-J Eng; 214 (4) (2000)

11. S. Zaborski, M. Łupak, D. Poroś, J Mater Process Tech 149, 1 (2004)

12. S. Roy, A. Bhattacharyya, S. Banerjee, Tribol INT 40, 9 (2007)

13. B. Lauwers, F. Klocke, A. Klink, CIRP Ann-Manuf Techn 63 (2) (2014)

14. D. T. Curtis, S.L. Soo, D. K. Aspinwall, CIRP AnnManuf Techn 58 (1) (2009)

15. V.A Mogilnikov, M. YaChmir, Yu. S. Timofeev, V. S. Poluyanov, Procedia CIRP 6 (2013)

16. N.N. Novikov, Structure and structure-sensitive properties of real crystals (Kiev: Vishcha School, 1983)

17. G.V. Samsonov, N.F. Pryadko, A.V. Pryadko. Electronic localization in a solid Moscow, Publishing (Mir Publishers, Moscow 1976)

18. W. Habrat, J. Porzycki, M. Krok, E. Socha, Mechanik 8-9 (2015)

19. K. E. Oczoś, W. Habrat, Mechanik 7 (2010)

20. K. E. Oczoś, W. Habrat, Mechanik 8-9 (2010). 